\section{RED-S: not just a female phenomenon}

\author{
Doug Bentall
}

\section{LONG-TERM LOVE OF CYCLING}

I ran as a schoolboy at both cross-country and middle distance athletics. After a knee injury at university, a school friend introduced me to the pleasures of cycling as a leisure pursuit. In my mid-30s, I joined my local cycle club and I continued to ride for leisure. My peak weight in my early 40 s was around $73 \mathrm{~kg}$. At the age of 48 , I regained my interest in cycling and started doing club time trials again. My performances were considerably slower after a 12-year break, and after another, year I decided to look for the help of a cycle trainer.

\section{TRANSFORMATION IN MIDDLE AGE}

Working with a trainer completely transformed my training and approach to cycling. My weight was now around $65 \mathrm{~kg}$; however, after a year of gradually increased training load, my weight dipped as low as $62.5 \mathrm{~kg}$. I did not make any effort to lose weight and I took advantage of the fact that I could eat more. I also did not really pay attention to the nutritional needs of being a competitive cyclist. After my first full year of training, I could beat my personal bests from my mid-30s, and investment in better cycle equipment helped to cut my times even further (figure 1).

\section{FURTHER WEIGHT LOSS}

I enjoyed the discipline of having my own cycle trainer, and after about 18 months with him, I underwent a package of tests. Despite a 12 per cent body fat percentage and a weight of $63.5 \mathrm{~kg}$, the trainer suggested I could lose a further kilogramme to improve power to weight ratio. I must admit I never did lose that kilogramme. I did not think it could make

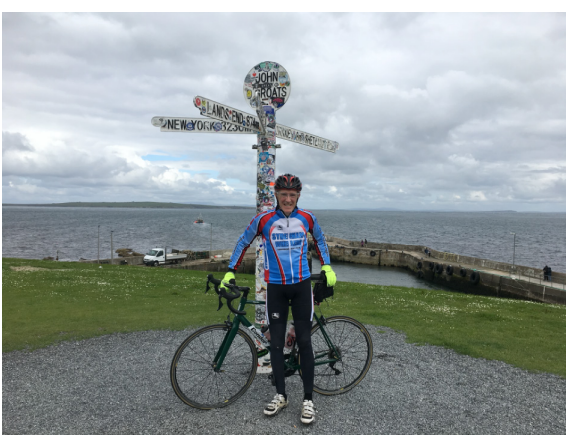

Figure 1 On my bike at John O'Groats. that much difference and my weight stayed stable.

When I went to see my general practitioner for a regular check-up, he observed the weight loss and asked if I was happy about it, which I was. A few friends commented on my looking very thin. After a while, I began to put this down to the fact that the obesity of the general population has recalibrated people's opinions of what is a healthy weight. My body mass index was still in the normal range, although fairly near the bottom end of it.

\section{NEW CHALLENGES}

When I hit 50, I was looking for a new challenge and a friend of mine suggested doing a duathlon. Having run as a child, I thought I would give it a try again, especially as I discovered I could now compete in the $50+$ age group. I am a much better runner than a cyclist, so I really began to enjoy it.

At the end of the year, I qualified for the European Age Group Duathlon in Spain in April 2017. I entered a local cross-country event and I won the 50 years + race, but afterwards, I had difficulty walking. In my opinion, I thought I had just pulled a hamstring as that was what my symptoms felt like. I took some painkillers and ran the Masters' event the next week, but the problem was still there. With the European Age Group Duathlon only a month away, I stopped running completely and stuck to the bike.

\section{DIAGNOSIS OF RELATIVE ENERGY DEFICIENCY IN SPORT (RED-S)}

I was eventually referred to a sports injury specialist, and to my astonishment, they told me that I had a stress fracture in my hip and my vitamin D levels were very low. With hindsight, I realised that I did not have a scan to assess my bone health, so I was not I given any advice or explanation about the cause of this stress fracture. Since then, I have been taking a supplement. I was planning to return to running after the injury healed, but I decided to give it 12 months' rest.

As well as this, I saw an article in a cycling magazine about a study on male cyclists $^{12}$. I was keen to take part as I thought that the scan they mentioned would show that I now had good bone health. Unfortunately, it showed that I had low bone density in my spine, which apparently is a classic symptom of RED-S in male cyclists. ${ }^{3}$

\section{THOUGHTS ABOUT RED-S}

Although the stress fracture had given me an inkling that all was not necessarily well with my bone density, the diagnosis still came as something of a shock. I had not heard of RED-S ${ }^{4}$ before, although I had seen a recent TV article on a young local girl runner who had developed osteoporosis at a very young age due to undernutrition and overtraining. I did think 'that's OK, I am not a girl, I'm not young and I eat plenty!'.

I read a few times in the cycling press that cyclists could be prone to developing osteoporosis, and in my case, I was eventually diagnosed with osteoporosis. Initially, I never paid that much attention to nutritional advice, but now I know I have been compromising my health, I am taking nutrition a whole lot more seriously. It is quite hard though. The media in general, the cycling media and perhaps even our whole culture, are very much focused on losing weight and the need to limit your calorie intake. I have to keep reminding myself that a lot of it simply does not apply to me.

\section{THREE KEY LEARNING POINTS FOR A \\ CLINICIAN DEALING WITH RED-S}

1. Coaches, physiotherapists and medical professionals need to be more aware of the possibility that keen amateur cyclists may unwittingly be developing this condition and that it can affect both women and men.

2. If you decide to take your training seriously, it can be very easy to underfuel yourself without meaning to and even without knowing what you are doing. It might take something like a stress fracture to show it.

3. There should be more education for keen amateur cyclists about RED-S and the importance of matching nutrition to training levels. ${ }^{5}$ I appreciate that many people may benefit greatly from losing weight, but there is not enough information available warning the lightweight middle-aged men in lycra to take care.

\section{Twitter Doug Bentall @dougbental}

Funding The authors have not declared a specific grant for this research from any funding agency in the public, commercial or not-for-profit sectors.

Competing interests None declared.

Patient consent for publication Obtained.

Provenance and peer review Commissioned; internally peer reviewed. 


\section{Patient voices}

(c) Author(s) (or their employer(s)) 2020. No commercial re-use. See rights and permissions. Published by BMJ.

\section{A Check for updates}

To cite Bentall D. Br J Sports Med 2020;54:1303-1304.

Accepted 23 February 2020

Published Online First 24 March 2020

Br J Sports Med 2020;54:1303-1304.

doi:10.1136/bjsports-2019-101868

\section{REFERENCES}

1 Keay N, Francis G, Hind K. Low energy availability assessed by a sport-specific questionnaire and clinical interview indicative of bone health, endocrine profile and cycling performance in competitive male cyclists. BMJ Open Sport Exerc Med 2018;4:e000424.

2 Keay N, Francis G, Entwistle I, et al. Clinical evaluation of education relating to nutrition and skeletal loading in competitive male road cyclists at risk of relative energy deficiency in sports (RED-S): 6-month randomised controlled trial. BMJ Open Sport Exerc Med 2019;5:e000523.
3 Mountjoy M, Sundgot-Borgen JK, Burke LM, et al. IOC consensus statement on relative energy deficiency in sport (RED-S): 2018 update. Br J Sports Med 2018:52:687-97.

4 Ackerman KE, Stellingwerff T, Elliott-Sale KJ, et al. \#REDS (Relative Energy Deficiency in Sport): time for a revolution in sports culture and systems to improve athlete health and performance. $\mathrm{Br} J$ Sports Med 2020;54:369-70.

5 BASEM. Health for performance, 2018. Available: http://health4performance.co.uk/ [Accessed 13 Jan 2020]. 